
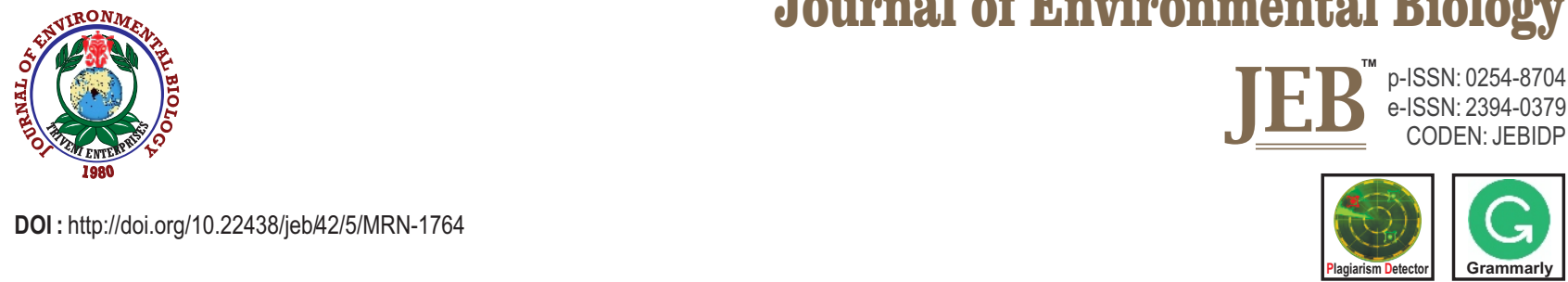

\title{
Molecular characterization of intraspecific variations in Helicoverpa armigera (Hübner) populations across India
}

\author{
S. Chakravarty ${ }^{1}$ K.G. Padwal' and C.P. Srivastava* ${ }^{2 *}$ \\ 'Department of Applied Agriculture, Rajiv Gandhi South Campus, Banaras Hindu University, Mirzapur- 231 001, India. \\ ${ }^{2}$ Department of Entomology and Agricultural Zoology, Institute of Agricultural Sciences, Banaras Hindu University, Varanasi - 221 005, India. \\ *Corresponding Author Email : csrivastava63@gmail.com
}

\section{Abstract}

Aim: The present study was undertaken to explore the genetic diversity among Helicoverpa armigera populations from varied geographic regions of India using mitochondrial cytochrome coxidase I (COI) gene fragments.

Methodology: The larval specimens of $H$. armigera collected from 20 locations were subjected to DNA extraction, PCR amplification of target gene, sequencing and then multiple sequence alignments.

Results: Based on COI sequence data, high levels of genetic differentiation among some $\mathrm{H}$. armigera populations were detected, but divergence existing was not high enough to delineate them as separate species. The Indian population as a whole exhibited similarity with global genetic assemblage. Significant negative neutrality test indices and unimodal mismatch distribution further supported that this insect experienced a demographic expansion in the past. The phylogenetic tree and median-joining haplotype network indicated that genetic similarity was not related with geographic proximity of populations.

Interpretation: Differences based on genetic analyses indicate considerable subspecific level variations among $H$. armigera populations of India. However, there is no existence of any unidentified cryptic species of $H$. armigera in the country.

Key words: COI gene, Diversity, Genetic structure, Haplotype, Phylogeny.

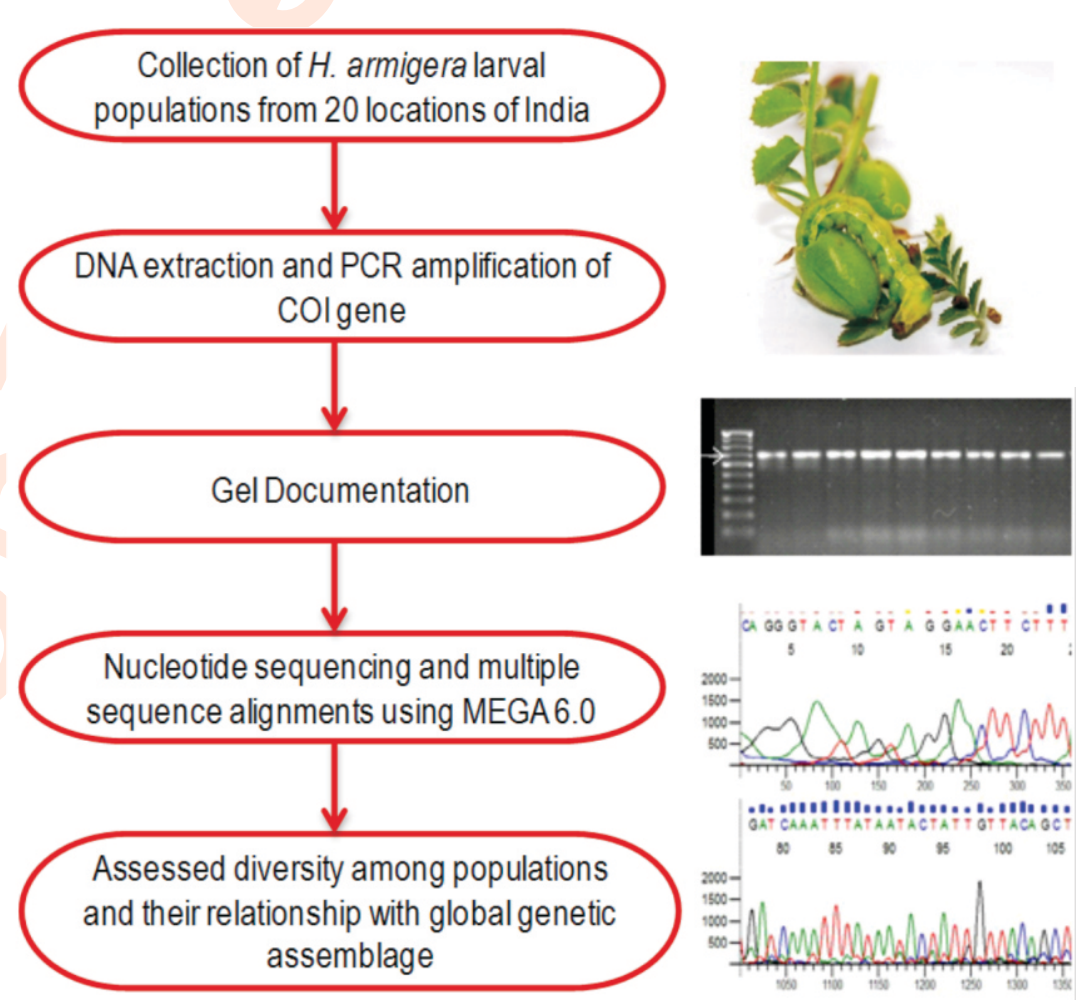

How to cite : Chakravarty, S., K.G. Padwal and C.P. Srivastava: Molecular characterization of intraspecific variations in Helicoverpa armigera (Hübner) populations across India. J. Environ. Biol., 42, 1320-1329 (2021). 


\section{Introduction}

The Heliothinae subfamily of noctuids includes some of the most damaging pests of agricultural importance throughout the world (Mitchell and Gopurenko, 2016). Among the different Helicoverpa or Heliothis species existing worldwide, three species that have been reported from India are Helicoverpa armigera (Hübner), Helicoverpa assulta (Guenée) and Heliothis peltigera (Denis and Schiffermüller), of which $H$. armigera is the most serious one (Ranjith and Chellappan, 2015). In India, it has been recorded feeding on 181 species of plants, distributed in nearly 45 families and out of these 96 species are agriculturally important crop plants (Srivastava et al., 2010). Depending on the crop, $H$. armigera induced damage can lead to 50 to 90 percent of yield loss (Chakravarty et al., 2018). The extent of damage caused by this insect on various crops under different agroclimatic zones has elevated its status to "a pest of national importance" in India (Sharma et al., 2010). The damage it causes is estimated to cost around 2 billion US dollars each year, apart from the environmental and socio-economic costs related to its control (Tay et al., 2013).

Looking at its ability to thrive on several hosts and its flexibility in rapidly developing resistance to almost all classes of insecticides, including Bacillus thuringiensis-derived toxins (Ranjith et al., 2010), it is doubted that there is an existence of strong genetic variability within Indian populations of $H$. armigera. The problem of resistance is estimated to be a few folds to few hundred folds to different groups of insecticides in various regions of our country (Armes et al., 1996). Even the resistance is also reported in $H$. armigera populations from those places in tribal regions where chemical control measures are hardly adopted (Deepa and Srivastava, 2011). On the other hand, sensitivity against various groups of insecticides also varies greatly among populations collected from different agro-climatic zones (Chaturvedi, 2013), arising the doubt regarding the existence of possible differences in the population genetic structure of Indian $H$. armigera. The different larval colour morphs of $H$. armigera also exhibit a differential susceptibility against various insecticides (Chakravarty et al., 2020), thereby rendering its management all the more difficult. There are also reports regarding Indian populations of $H$. armigera exhibiting differential responses to parasitoids (Romeis and Shanower, 1996) and pheromones (Tamhankar et al., 2003).

$H$. armigera is also a known facultative migrant (Nibouche et al., 1998). Its ability to undertake long-distance flights may cause intermingling of exotic populations with native ones, giving rise to the possibilities of developing new species and subspecies. Likewise, in diverse habitats existing such as those in India, the tendency to fly across different agro-climatic zones and mixing with native populations thriving on various host plants could lead to the possibility of occurrence of unknown subspecies of $H$. armigera (Behere et al., 2013). These possible changes in the genetic make-up of the insect population due to the formation of new species or subspecies again could be the reason for differential susceptibility or resistance development to various selection pressures in different agro-climatic zones. Limited studies regarding the existence of phenotypic differences among varied host-associated populations of $H$. armigera (Gill et al., 2015) has further hinted that the populations occurring at different geographical locations and on different host plants across India are genetically diverse.

The adaptability of any species to environmental change largely depends on the genetic structure of its populations (Sambathkumar et al., 2017). Thus, understanding the genetic diversity in Indian $H$. armigera has become necessary to elucidate the actual cause for the occurrence of such variations in the physiological and behavioural characteristics of this pest in the country, as well as for development and deployment of long term effective management strategies (Subramanian and Mohankumar, 2006). Molecular markers are considered as important tools for assessment of inter-population genetic differences in insects (Sun et al., 2011). The cytochrome $c$ oxidase subunit I (COI) region of mitochondrial DNA is particularly useful for determining intra- and inter specific complexities, as well as in elucidating phylogenetic relationships at the genus and species level, and within families (Hallerman, 2021). There are also several evidences that have proved that variations in the mitochondrial DNA genes influence the process of speciation in closely related cryptic species in several insect orders, including lepidoptera (Karthika et al., 2019). Hence in the present study, we sought to determine the variations within Indian populations of $H$. armigera based on COI gene.

\section{Materials and Methods}

Sample collection and DNA extraction: Larvae of $H$. armigera were collected from 20 different geographical locations falling under four major pulse growing zones of India, during March, 2015 to February, 2018. These locations were Ludhiana (HLUD; $30^{\circ} 54^{\prime} \mathrm{N}, 75^{\circ} 48^{\prime} \mathrm{E}$ ), Hissar (HHIS; 29¹0' N, 7542' E), Delhi (HDHL; $\left.28^{\circ} 64^{\prime} \mathrm{N}, 77^{\circ} 16^{\prime} \mathrm{E}\right)$, Pantnagar (HPNT; 2901' N, 7948' E) and Udaipur (HUDP; $24^{\circ} 34^{\prime} \mathrm{N}, 73^{\circ} 42^{\prime} \mathrm{E}$ ) of North West Plain Zone; Kanpur (HKNP; 2649' N, 80²7' E), Ayodhya (HFZB;

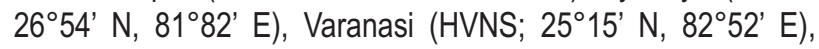
Samastipur (HSMP; 25 $98^{\prime} \mathrm{N}, 85^{\circ} 67^{\prime} \mathrm{E}$ ) and Cooch Behar (HCBR; 26 $40^{\prime} \mathrm{N}, 89^{\circ} 38^{\prime} \mathrm{E}$ ) of North East Plain Zone; Jabalpur (HJBP; $\left.23^{\circ} 21^{\prime} \mathrm{N}, 79^{\circ} 96^{\prime} \mathrm{E}\right)$, Raipur (HRPR; $21^{\circ} 14^{\prime} \mathrm{N}, 81^{\circ} 42^{\prime} \mathrm{E}$ ), Nagpur (HNGP; $\left.21^{\circ} 08^{\prime} \mathrm{N}, 79^{\circ} 04^{\prime} \mathrm{E}\right)$, Akola (HAKL; 2042' N, $77^{\circ} 01^{\prime} \mathrm{E}$ ) and Pune (HPNE; 18 $31^{\prime} \mathrm{N}, 73^{\circ} 51^{\prime} \mathrm{E}$ ) of Central Zone, and Hyderabad (HHYD; $\left.17^{\circ} 50^{\prime} \mathrm{N}, 78^{\circ} 27^{\prime} \mathrm{E}\right)$, Raichur (HRCR; $\left.16^{\circ} 11^{\prime} \mathrm{N}, 77^{\circ} 19^{\prime} \mathrm{E}\right)$, Bagalkot (HBGK; 16¹0' N, 7541' E), Bengaluru (HBGL; $13^{\circ} 07^{\prime} \mathrm{N}, 77^{\circ} 56^{\prime} \mathrm{E}$ ) and Coimbatore (HCBT; $\left.11^{\circ} 01^{\prime} \mathrm{N}, 76^{\circ} 92^{\prime} \mathrm{E}\right)$ of South Zone. The species identity of collected specimens was confirmed as $H$. armigera morphologically using keys provided by Passoa (2014). The 
samples were then stored in $95 \%$ ethanol at $-20^{\circ} \mathrm{C}$ for performing the molecular investigations. The genomic DNA was extracted separately from four individual late instar larvae of each location (population). The extraction was carried out from the larval skin following the procedure described by Murray and Thompson (1980) with some modifications. The quality of extracted DNA samples was checked on $0.8 \%$ agarose gel and quantified using UV spectrophotometer (Elico® SL191) as per Anno et al. (1998).

PCR amplification and sequencing of COI gene: The DNA extracts were subjected to PCR amplification of a 658 bp region of the 5 ' terminus of the $\mathrm{COI}$ gene following standard protocols as described by Shashank et al. (2014) using the primers LCO1490 (forward) and HCO2198 (reverse) as described by Folmer et al. (1994). The amplifications were performed in a $25 \mu \mathrm{l}$ volume reaction mixture containing $2 \mu$ l of DNA template (100ng), $2 \mu \mathrm{l}$ of PCR buffer (10X), $0.5 \mu$ l of Taq polymerase (1U, GeNei ${ }^{\mathrm{TM}}$ ), $1 \mu \mathrm{l}$ each of specific primers (10pmol), dNTP (2mM) and $\mathrm{MgCl}_{2}$ $(2 \mathrm{mM})$, and $17.5 \mu \mathrm{l}$ of nuclease free water. Thermo cycling consisted of following steps: initial denaturation at $94^{\circ} \mathrm{C}$ for $5 \mathrm{~min}$; followed by 30 cycles of amplification, each cycle with the following schedule: denaturation for $30 \sec$ at $94^{\circ} \mathrm{C}$, annealing for 45 seconds at $50^{\circ} \mathrm{C}$ and extension for $1 \mathrm{~min}$ at $72^{\circ} \mathrm{C}$. This was followed by final extension at $72^{\circ} \mathrm{C}$ for $5 \mathrm{~min}$. The amplification products were electrophoresed on $1 \%$ agarose gel having $0.05 \mu \mathrm{g}$ $\mathrm{ml}^{-1}$ ethidium bromide and sequenced by Sanger's method using ABI3730xI DNA sequencer (Applied Biosystems, USA) and Big Dye Terminator v3.1 kit (Applied Biosystems, USA) at M/s Eurofins Analytical Services India Pvt. Ltd. (Bengaluru, India).

Sequences alignment and data analysis: All the $H$. armigera COI gene sequences were imported into FASTA format for alignment and trimming in ClustalW algorithm by setting default parameters in the MEGA version 6.0 software package (Tamura et al., 2013). Sequences were analyzed based on homologs of the gene when subjected to nucleotide BLAST (Basic Local Alignment Search Tool) of NCBI (https://www.ncbi.nlm.nih.gov/) and then submitted to NCBI for obtaining GenBank accessions. DnaSP version 5.0 software (Rozas et al., 2003) was used to analyze the diversity indices like the number of haplotypes $(\mathrm{Hn})$, haplotype diversity $(\mathrm{Hd})$, nucleotide diversity $(\pi)$, number of polymorphic sites (S) and average number of nucleotide differences among haplotypes (k). Further, to ascertain demographic history and evolutionary neutrality of $H$. armigera COI sequences, tests like Tajima's $D$ (Tajima, 1989) and Fu's Fs (Fu, 1997), and mismatch distribution analysis (Rogers and Harpending, 1992) were also performed using DnaSP 5.0. The average pairwise sequence divergences among $H$. armigera populations were estimated using the Kimura 2-parameter distance model (Kimura, 1980) and displayed graphically in a neighbour-joining (NJ) tree, using MEGA 6.0, with a confidence level of 1000 bootstrap replicates. The number of sites with transitions (Ts) and transversions (Tv) from aligned sequences, analysis of molecular variance (AMOVA) and pairwise genetic differentiation $\left(F_{\mathrm{ST}}\right)$ between populations were calculated in Arlequin version 3.5 (Excoffier and Lischer, 2010). The levels of genetic differentiation were categorized as $F_{\mathrm{ST}}<0.05$ (low), 0.05 $\leq F_{\mathrm{ST}}<0.15$ (moderate), $0.15 \leq F_{\mathrm{ST}}<0.25$ (high), $F_{\mathrm{ST}} \leq 0.25$ (very high). The haplotype network was constructed using a medianjoining algorithm in Network 4.6.1.1 software (Bandelt et al., 1999).

\section{Results and Discussion}

The sequences for 80 individuals sampled across India showed high similarity (100 percent query coverage and 99 percent identity) to $H$. armigera $\mathrm{COI}$ gene sequences already deposited in the NCBI-GenBank database, and thus the specimens were confirmed to be $H$. armigera and used for diversity analyses. Further, for comparison of Indian populations with global genetic assemblage, 20 additional COI gene sequences were mined from NCBI database. These sequences represented populations of 14 different countries outside India, based on the spread of $H$. armigera. Inclusion of these additional sequences produced a final alignment of 620 base pairs for 100 individuals. Sample size disparity is due to lack of sequence information from different countries. The sequence region showed high Adenine (A) + Thymine (T) content $30.35 \%$ A and $40.64 \% \mathrm{~T}$, averaged across the multiple sequence alignment), in accordance with insect mitochondrial DNA(Sambathkumar et al., 2017; Shashank et al., 2018). The mean composition of Cytosine (C) and Guanine $(G)$ in the sequences was $14.85 \%$ and $14.16 \%$, respectively (Table 1 ).

The molecular diversity indices generated for the $100 \mathrm{COI}$ gene sequences, in which Indian and foreign sequences were analyzed as discrete units, indicated about the existence of considerable differences among them (Table 1). A total of 52 polymorphic sites were observed in the $\mathrm{COI}$ gene sequences of the studied populations, showing both transitional and transversional substitutions. The nucleotide diversity $(\pi)$ was found to be low in case of both the Indian (0.0910) as well as foreign (0.00269) populations. However, the populations were characterized by high values of haplotype diversity $(\mathrm{Hd})$, i.e., $0.954,0.853$ and 0.948 for Indian, foreign and combined population sets, respectively. Furthermore, among the different Indian populations of $H$. armigera, the populations from North West Plain Zone had the highest number of haplotypes $(H n=13)$ and gene diversity $(\mathrm{Hd}=0.953 \pm 0.028)$, while the South Zone populations exhibited highest nucleotide diversity $(\pi=0.01410)$ and the average number of genetic differences among haplotypes $(k=8.742)$. In contrast, the Central Zone population set was lowest in all concerns $(\mathrm{Hn}=9, \mathrm{Hd}=0.847, \pi=0.00500$ and $\mathrm{k}=3.100$ ).

The mismatch nucleotide frequency spectra (distribution of pairwise differences) for the studied pest species are shown in 
Table 1 : Molecular diversity indices and demographic history parameters of different $H$. armigera populations, assessed using mitochondrial COI gene sequences

\begin{tabular}{|c|c|c|c|c|c|c|c|}
\hline \multirow[t]{2}{*}{ Index } & \multicolumn{5}{|c|}{ Indian population } & \multirow[t]{2}{*}{ Foreign population } & \multirow[t]{2}{*}{ Total } \\
\hline & NWPZ & NEPZ & $\mathrm{CZ}$ & SZ & Pooled & & \\
\hline$n$ & 20 & 20 & 20 & 20 & 80 & 20 & 100 \\
\hline $\mathrm{Hn}$ & 13 & 11 & 9 & 12 & 39 & 8 & 43 \\
\hline $\mathrm{Hd} \pm \mathrm{SD}$ & $0.953 \pm 0.028$ & $0.921 \pm 0.037$ & $0.847 \pm 0.061$ & $0.949 \pm 0.028$ & $0.954 \pm 0.012$ & $0.853 \pm 0.059$ & $0.948 \pm 0.028$ \\
\hline$\pi$ & 0.00750 & 0.00603 & 0.00500 & 0.01410 & 0.00910 & 0.00269 & 0.00805 \\
\hline k & 4.647 & 3.737 & 3.100 & 8.742 & 5.642 & 1.663 & 4.980 \\
\hline S & 16 & 19 & 14 & 36 & 48 & 6 & 51 \\
\hline Ts & 10 & 10 & 8 & 9 & 19 & 6 & 22 \\
\hline Tv & 8 & 10 & 7 & 27 & 32 & 0 & 32 \\
\hline \multicolumn{8}{|c|}{ Nucleotide composition (Relative values) } \\
\hline$A(\%)$ & 30.56 & 30.35 & 30.24 & 30.34 & 30.36 & 30.28 & 30.35 \\
\hline$C(\%)$ & 14.94 & 14.79 & 14.85 & 14.83 & 14.85 & 14.89 & 14.85 \\
\hline $\mathrm{G}(\%)$ & 13.90 & 14.12 & 14.10 & 14.48 & 14.16 & 14.11 & 14.16 \\
\hline $\mathrm{T}(\%)$ & 40.60 & 40.74 & 40.81 & 40.35 & 40.63 & 40.72 & 40.64 \\
\hline \multicolumn{8}{|c|}{ Neutrality tests } \\
\hline Fu's Fs & $-4.1487^{*}$ & $-2.8853^{\text {NS }}$ & $-1.6368^{\mathrm{NS}}$ & $-0.5794^{\mathrm{NS}}$ & $-22.8404^{\star *}$ & $-2.9480^{\mathrm{NS}}$ & $-25.4363^{\star *}$ \\
\hline Tajima's $D$ & $-0.3161^{\mathrm{NS}}$ & $-1.2810^{\mathrm{NS}}$ & $-0.9845^{\mathrm{NS}}$ & $-0.5487^{\mathrm{NS}}$ & $-1.3569^{*}$ & $-0.1542^{\mathrm{NS}}$ & $-1.5732^{*}$ \\
\hline
\end{tabular}

Abbreviations - $n$ : number of sequences, Hn: number of haplotypes, $\mathrm{Hd}$ : haplotype diversity, SD: standard deviation of haplotype diversity, $\pi$ : nucleotide diversity, k: average number of nucleotide differences (genetic differences) among haplotypes, S: number of polymorphic (segregating) sites, Ts: number of sites with transitions, Tv: number of sites with transversions, A: Adenine, C: Cytosine, G: Guanine, T: Thymine, NWPZ: North West Plain Zone, NEPZ: North East Plain Zone, CZ: Central Zone, SZ: South Zone. Asterisks represent significance levels: ${ }^{*} P\left\langle 0.05\right.$, ${ }^{* *} P\langle 0.01$; NS: Non-significant $(P>$ 0.10). Here "Pooled" denotes all the populations occurring in four major pulse growing zones of India and "Total" denotes combined set of Indian and foreign populations.

Fig. 1. The observed distribution was unimodal for the Indian, foreign as well as combined population sets, indicating a demographic expansion in the past. This result was further supported by significant negative values in Tajima's D test (1.3569 and $-1.5732, P<0.05)$ and Fu's $F$ test $(-22.8404$ and $25.4363, \mathrm{P}<0.01)$ for the pooled Indian and total populations, respectively (Table 1). Significant and negative neutrality test indices also indicate an excess of low-frequency polymorphism and are in accordance with either purifying selections or population expansion. These results are also congruent with earlier studies on several lepidopteran pest population diversity analyses from India such as Leucinodes orbonalis (Karthika et al., 2019), Tuta absoluta (Shashank et al., 2018), Maruca vitrata (Chatterjee et al., 2019) and Pectinophora gossypiella (Naik et al., 2020), apart from H. armigera (Leite et al., 2014) in Brazil. The AMOVA analysis (Table 2 ) revealed that $93.51 \%$ of total genetic variation was partitioned within Indian and foreign population sets and the remaining $6.49 \%$ was partitioned among populations $\left(F_{\mathrm{ST}}\right.$ $=0.06494, P<0.01)$. Additionally, only $13.23 \%$ genetic variation was among the Indian populations from different zones, while $86.77 \%$ genetic variation was within zone populations $\left(F_{\mathrm{ST}}=\right.$ $0.13229, P<0.001)$. This amount of variance is highly significant and reveals that there is considerable population genetic structure.
The level of intraspecific differentiation among Indian populations was further assessed by calculating the pairwise Kimura-2-Parameter based genetic distance and genetic differentiation $\left(F_{\mathrm{ST}}\right)$ values (Table 3). Corrected pairwise genetic distances among studied populations varied from 0.000 to 0.040 with highest evident between the Coimbatore and Kanpur populations of South and North West Zones, respectively. The genetic distance for most of the specimens from geographically adjacent locations ranged from 0.000 to 0.005 , indicating not much variation within the populations of these locations from each other. The intra-population divergence for this gene was also found to be negligible. However, some of the populations collected from distant locations also exhibited very high similarity. This reveals that isolation by distance is not always expected in species like $H$. armigera having high mobility (Behere et al., 2013). Overall mean genetic distance was 0.015 . The pairwise $F_{\mathrm{ST}}$ values ranged from -0.076 to 0.649 , and many of them were significantly different. Out of 190 comparisons, only 35 showed low to moderate differentiation and the remaining showed high to very high genetic differences. These results also marked out signs of significant spatial population divergence.

Topologies of neighbour-joining tree indicated that all the studied Indian populations belonged to a single major clade, 


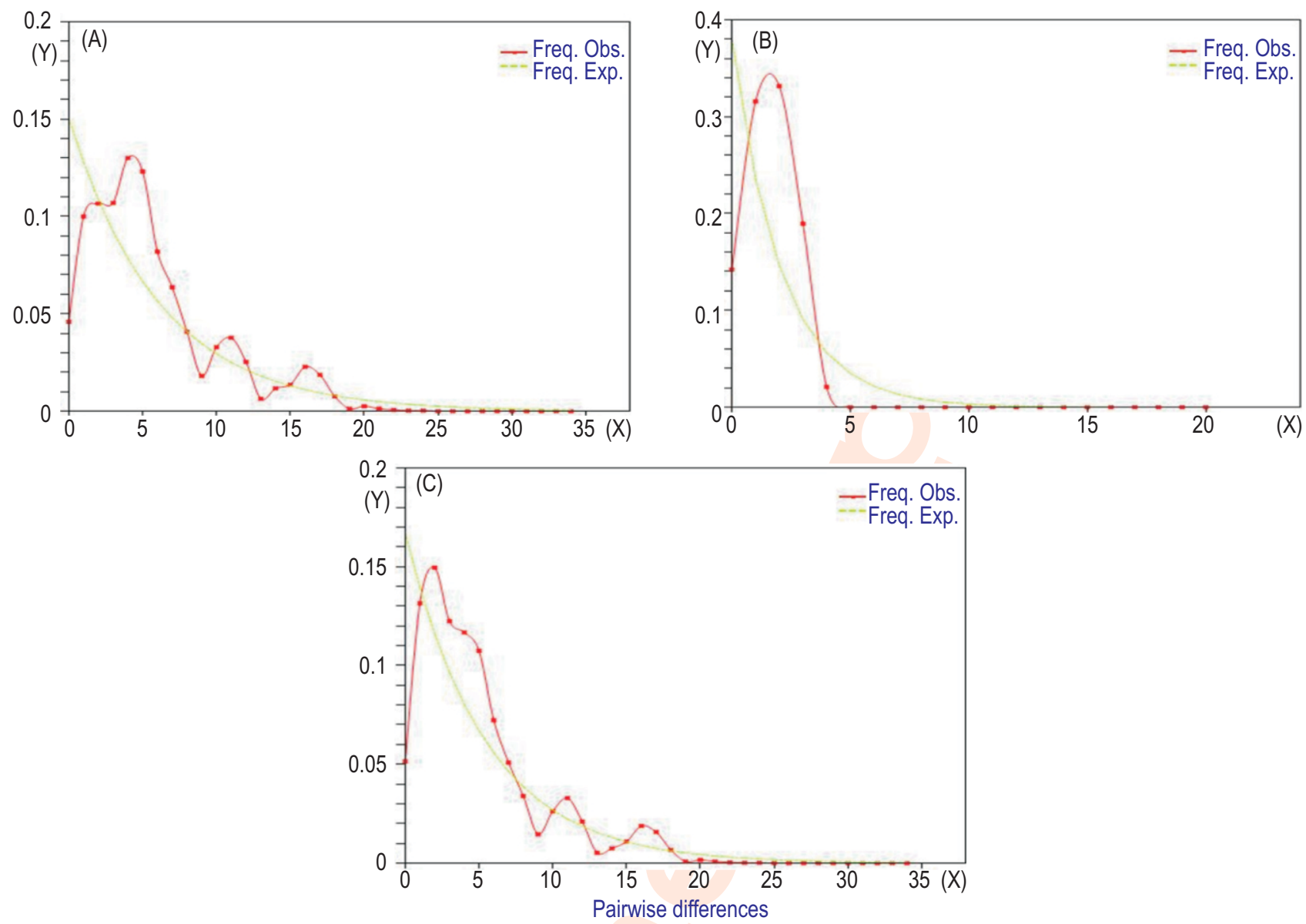

Fig. 1 : Frequencies of the observed and expected pairwise nucleotide differences (the mismatch distribution) in $H$. armigera (A: Indian populations; B: Foreign populations; C: Combined set of Indian and foreign populations). X-axis (x): number of pairwise differences; $Y$-axis (y): frequency of mismatches; Freq. Exp.: frequency expected (green dashed line) and Freq. Obs: frequency observed (red solid line).

Table 2 : Analysis of molecular variance (AMOVA) for the mitochondrial COI gene sequences among and within different populations of $H$. armigera

\begin{tabular}{lccll}
\hline Source of variation & df & \multicolumn{1}{c}{ Sum of squares } & Variance components & Percentage of variation \\
\hline A. Comparison of Indian and foreign population sets & & \\
Among populations & 1 & 7.847 & $0.16913 \mathrm{Va}$ & 6.49 \\
Within populations & 98 & 238.663 & $2.43533 \mathrm{Vb}$ & 93.51 \\
Total & 99 & 246.510 & 2.60446 & 100 \\
Fixation index, $F_{\mathrm{ST}}: 0.06494^{* *}$ & & & \\
B. Comparison of Indian population sets occurring in different zones & & \\
Among zones & 3 & 30.713 & $0.38546 \mathrm{Va}$ & 13.23 \\
Within zones & 76 & 192.150 & $2.52829 \mathrm{Vb}$ & 86.77 \\
Total & 79 & 222.863 & 2.91375 & 100 \\
Fixation index, $F_{\mathrm{ST}}: 0.13229^{* * *}$ & & & \\
\hline
\end{tabular}

Asterisks represent significance levels: ${ }^{* \star} P<0.01,{ }^{* \star *} P<0.001$; df: Degree of freedom

however, distinct subclades were also observed (Fig. 2). But within these subclades, there were no significant genealogical branches or clusters of samples corresponding to sampling sites or zones. $\mathrm{H}$. armigera $\mathrm{COI}$ gene sequences deposited in the
GenBank database from other countries also shared similarity with studied sequences, indicating that Indian populations are ancestrally related to the world population. However, isolates from Australia and New Zealand formed a distinctive separate 
Table 3: Pairwise $F_{\mathrm{ST}}$ (below diagonal) and genetic distance (above diagonal) amongst different populations of $H$. armigera in India based on mitochondrial $\mathrm{COI}$ gene sequences

\begin{tabular}{|c|c|c|c|c|c|c|c|c|c|c|c|c|c|c|c|c|c|c|c|c|}
\hline opu & & 2 & 3 & 4 & 5 & 6 & 7 & 8 & 9 & 10 & 11 & 12 & 13 & 14 & 15 & 16 & 17 & 18 & 19 & 20 \\
\hline UD & - & 1 & & & & & & & & & & & & & & & & & & \\
\hline & & & & & & & & & & & & & & & & & & & & 0.038 \\
\hline & & 0.098 & & & & & & & & & & & & & & & & & & \\
\hline & & & 90 & - & & & & & & & & & & & & & & & & 0.033 \\
\hline & & 0.428 & & 0.287 & & 0.016 & & & & & & & & & & & & & & 0.028 \\
\hline & & & & 0.127 & & - & 0.0 & & & & & & & & & & & & & 40 \\
\hline & & & & 0. & & 0.1 & - & & & & & & & & & & & & & 0.028 \\
\hline & & & & & & & & & & & & & & & & & & & & \\
\hline & & & & & & & & & & & & & & & & & & & & 26 \\
\hline & & & & & & & & & & 7 - & & & & & & & & & & 0.036 \\
\hline & & & & & & & & & & & - & & & & & & & & & 030 \\
\hline & & & & & & & & & & & & & & & & & & & & 0.030 \\
\hline & & & & & & & & & & & & & & 0.0 & & & & & & 0.030 \\
\hline & & 0. & & 0. & & & & & & & & & & & 0.003 & & & & & 28 \\
\hline & & 40. & & & & & & & & & & & & & & 0.008 & & & & 0.028 \\
\hline AYD & 98 & 0.4 & 50. & 0.417 & 70. & 0. & 0.6 & & & & & $6-0$ & & & & & 0.011 & 0.013 & 30 & 0.030 \\
\hline & 0 & 0. & & 0.212 & 20.4 & & 0.0 & & & & & & -0 & 60. & 0.2 & & & 0.008 & & 0.031 \\
\hline N & & 20.4 & & 0.4 & 10. & & & & & & & & & & & & & - & 0.0 & 0.033 \\
\hline & & 40.3 & & 0.2 & & & & & & & & & & & & & & & & 0.023 \\
\hline CBT & & 7 & & 0 & & & 0 & & & & 0. & & & & & & & & & \\
\hline
\end{tabular}

$F_{\mathrm{ST}}$ values in bold are significant after sequential Bonferroni correction $(P<0.05)$.

clade, and thus seem to have an ancestral difference from the populations considered in this study. The phylogeny also revealed that Heliothis peltigera is basal to Helicoverpa assulta, which in turn basal to $H$. armigera. All the populations also displayed a large number of mitochondrial haplotypes for the $\mathrm{COI}$ gene, of which 13 were shared and 26 unique (Fig. 3). Of the total shared haplotypes, haplotype 14, 18, 19 and 35 were highly common and shared by many locations or countries, while remaining were at least shared by two populations. However, the COI haplotype network was complex and there was no obvious pattern regarding the distribution of observed haplotypes in terms of geographical locations of the studied discrete populations.

Thus, characterization of different geographic populations of $H$. armigera from India based on $\mathrm{COI}$ gene indicated that these populations were not homogenous and maximum sequence divergence was up to four percent. However, Hebert et al. (2010) suggested that divergence of more than five percent in the COI gene amplicon depicts the likely occurrence of a new species in Lepidoptera. So the genetic divergence existing among the Indian populations of $\mathrm{H}$. armigera is not high enough to delineate them as cryptic species, but the possibility of the existence of subspecies cannot be ruled out, as the intraspecific divergence is substantially higher than the postulated level of $<3$ percent as per Hebert et al. (2003). The phylogenetic tree also showed the presence of all the studied Indian populations into a common major clade, and this again strongly supported the single species status of $H$. armigera in the country. However, clustering of populations into separate sub clades indicated about the existence of strong variability among them. All these sub clades were complex, as they included populations from geographically distant locations, thereby suggesting high gene flow among the populations in the region. The high migratory potential of the adult moths of this insect (Nibouche et al., 1998) might have resulted in an intermingling of populations from different locations, as also observed in the complex haplotype network.

The presence of cryptic species of this insect in India was also not supported by Behere et al. (2007) based on the analyses of partial COI gene from $90 \mathrm{H}$. armigera specimens collected from northern, central and southern parts of the country. However, Asokan et al. (2012) indicated the possibility of emerging hostassociated genetic differences in Indian populations of $H$. armigera. In this study also, it was apparent that there were a small number of populations particularly from the South Zone of the country that was significantly structured from all other sampled populations. High genetic differentiation of such populations may be the result of natural barriers that limited gene flow by blocking the spread of this mobile insect northward towards other zones. Indian $\mathrm{H}$. armigera also showed high intra-population haplotype diversity. This indicates that it has a strong adaptability to varied environments. The occurrence of several unique haplotypes can be attributed to different eco-environmental conditions and vegetation patterns in India, along with wide distribution range of 


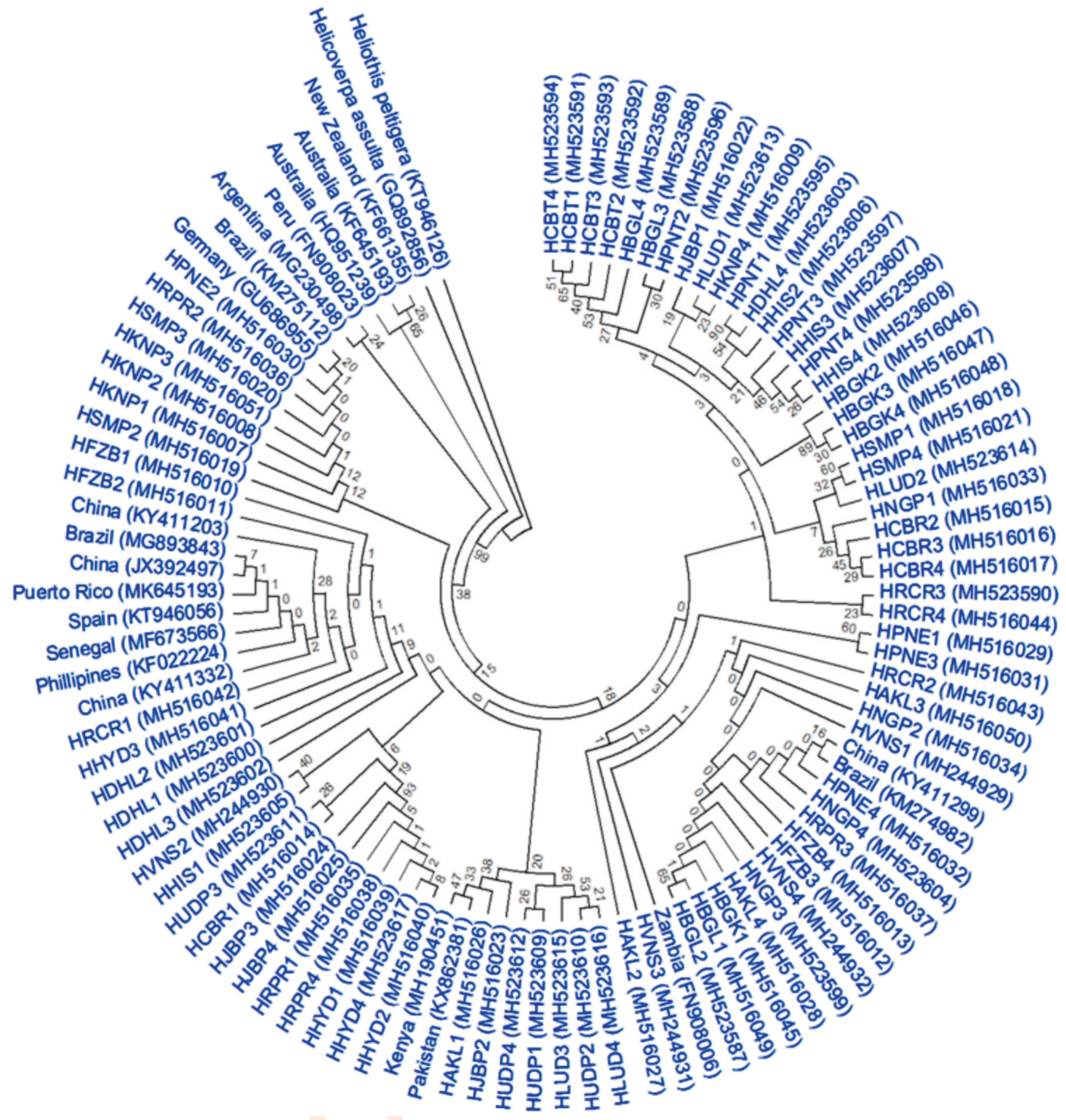

Fig. 2 : Neighbour-joining tree based on Kimura-2-Parameter distances showing clustering of $H$. armigera populations for mitochondrial $\mathrm{COI}$ gene sequences. Numbers at branch point indicate 1000 bootstrap value. Helicoverpa assulta (accession\# GQ892856) and Heliothis peltigera (accession\# KT946126) were used as outlier sequences.

H. armigera. Similar trends have also been observed by Sun et al. (2011) and Xu et al. (2019) for other insect pests. Variations at the genetic level of this pest species from India have also been reported by Subramanian and Mohankumar (2006); Deepa and Srivastava (2011); Behere et al. (2013) and Venkatesan et al. (2016), using other molecular markers.
The molecular evidences presented in this study thus seem to confirm substantial subspecific level variations among different geographic populations of $H$. armigera in India. Existence of such strong genetic variability within Indian $H$. armigera is the actual reason because of which it is exhibiting variability in its physiological characters and thereby differential 


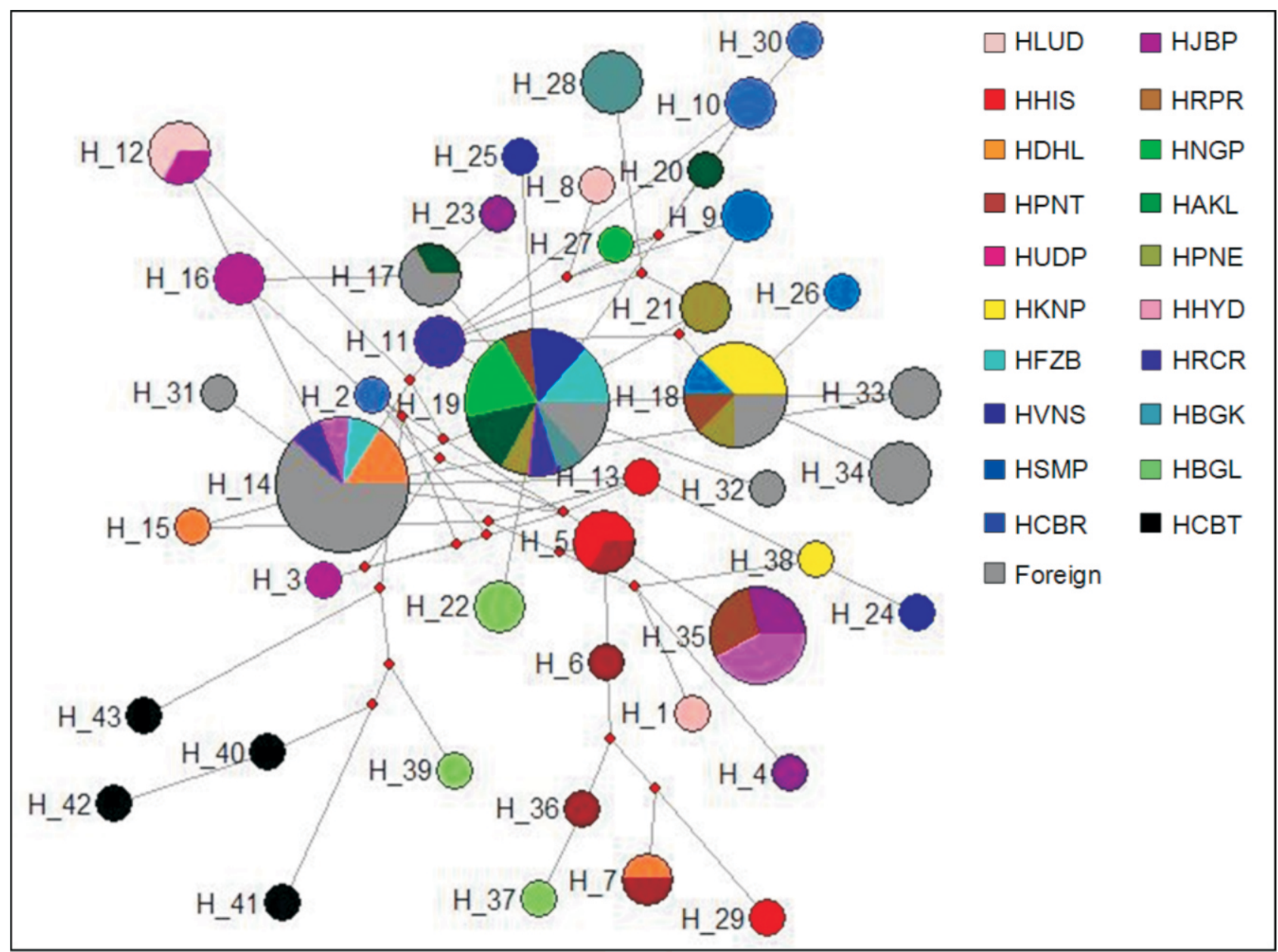

Fig. 3 : Median-joining haplotype network of $H$. armigera based on mitochondrial $\mathrm{COI}$ gene. Here, each circle (node) represents a haplotype and its area is proportional to haplotype frequency. Colours within the nodes refer to $\mathrm{H}$. armigera sampling regions. Small red dots represent median vectors (hypothetical extinct or unsampled haplotypes).

response to various selection pressures. However, there is no existence of any unidentified cryptic species of $H$. armigera in the country. The findings of the present study strengthen information concerning the population structure of $H$. armigera in India and will also be helpful in developing appropriate integrated management strategies for this pest in the country.

\section{Add-on Information}

Author's contribution : S. Chakravarty: Contribution: Collected the insect samples, performed the experiments, data analysis, and prepared the first draft of the manuscript; K. G. Padwal: Helped in data analysis and interpretation, and edited the manuscript draft; C.P. Srivastava: Designed the study, supervised the experiments, and evaluated and finalized the manuscript draft.

Research content : The research content of manuscript is original and has not been published elsewhere.

Ethical approval : NotApplicable

Conflict of interest : The authors declare that there is no conflict of interest.

Data from other sources : NotApplicable

Consent to publish : All authors agree to publish the paper in Journal of Environmental Biology.

\section{Acknowledgments}

We thank Prof. R. Chand and Prof. V. K. Mishra (Banaras Hindu University, India) for their valuable suggestions during the planning and course of the study, and Dr. B. Nawade (Agricultural Research Organization, Israel) and Dr. S. Nawathe (Agharkar Research Institute, India) for their technical support. 


\section{References}

Anno, A.D., M. Fabiano, G.C.A. Duineveld, A. Kok and R. Danavaro: Nucleic acid (DNA, RNA) quantification and RNA/DNA ratio determination in marine sediments: comparison of spectrophotometric, fluorometric and high performance liquid chromatography methods and estimation of detrital DNA. Appl. Environ. Microbiol., 64, 3238-3245(1998).

Armes, N.J., D.R. Jadhav and K.R. DeSouza: A survey of insecticide resistance in Helicoverpa armigera in the Indian sub-continent. Bull. Entomol. Res., 86, 499-514 (1996).

Asokan, R., K.B. Rebijith, N.K. Krishnakumar and M. Manamohan: Genetic diversity of tomato fruit borer, Helicoverpa armigera (Hübner) (Lepidoptera: Noctuidae) inferred from mitochondrial cytochrome oxidase-I (mtCO-I). Pest Manag. Hort. Ecosyst., 18, 29-34 (2012).

Bandelt, H.J., P. Forster and A. Röhl: Median-joining networks for inferring intraspecific phylogenies. Mol. Biol. Evol., 16, 37-48 (1999).

Behere, G.T., W.T. Tay, D.A. Russell, D.G. Heckel, B.R. Appleton, K.R. Kranthi and P. Batterham: Mitochondrial DNA analysis of field populations of Helicoverpa armigera (Hübner) (Lepidoptera: Noctuidae) and of its relationship to H. zea. BMC Evol. Biol., 7, 117 (2007).

Behere, G.T., W.T. Tay, D.A. Russell, K.R. Kranthi and P. Batterham: Population genetic structure of the cotton bollworm Helicoverpa armigera (Hübner) (Lepidoptera: Noctuidae) in India as inferred from EPIC-PCR DNAmarkers. PLoS ONE, 8, e53448 (2013).

Chakravarty, S., C.P. Srivastava and R. Keval: Biology of Helicoverpa armigera (Hübner) (Lepidoptera: Noctuidae) on chickpea-based artificial diet under laboratory conditions. Ann. PI. Protec. Sci., 26, 265-269 (2018).

Chakravarty, S., K.G. Padwal and C.P. Srivastava: Larval body colour polymorphism in Helicoverpa armigera (Hübner) populations across India. Indian J. Entomol., 82, 415-422 (2020).

Chatterjee, M., J. Yadav, S. Venilla, P.R. Shashank, N. Jaiswal, R. Sreevathsha and U. Rao: Diversity analysis reveals genetic homogeinity among Indian populations of legume pod borer, Maruca vitrata (F.). 3Biotech, 9, 319(2019).

Chaturvedi, I.: A survey of insecticide resistance in Helicoverpa armigera in Central and South Indian cotton ecosystems. Int. J. Res. Biosciences, 2, 37-43 (2013).

Deepa, M. and C.P. Srivastava: Genetic diversity in Helicoverpa armigera (Hübner) from different agroclimatic zones of India using RAPD markers. J. Food Legumes, 24, 313-316 (2011).

Excoffier. L. and H.E. Lischer: Arlequin suite ver. 3.5: a new series of programs to perform population genetics analyses under Linux and Windows. Mol. Ecol. Resour., 10, 564-567 (2010).

Folmer, O., M. Black, W. Hoeh, R. Lutz and R. Vrijenhoek: DNA primers for amplification of mitochondrial cytochrome $c$ oxidase subunit 1 from diverse metazoan invertebrates. Mol. Marine Biol. Biotechnol., 3, 294-299 (1994).

Fu, Y.X.: Statistical tests of neutrality of mutations against population growth, hitch hiking and background selection. Genetics, 147, 915-925 (1997).

Gill, A.K., R. Arora and P.C. Pathania: Morphological characterization of Helicoverpa armigera (Hübner) populations from various hosts in Punjab. Agric. Res. J., 52, 73-78 (2015).

Hallerman, E.M.: Applications and limitations of DNA barcoding in environmental biology. J. Environ. Biol., 42, 1-13 (2021).

Hebert, P.D.N., A. Cywinska and S.L. Ball: Biological identifications through DNA barcodes. Proc. R. Soc. B., 270, 313-321 (2003).

Hebert, P.D.N., J.R. deeWaard and J. Landry: DNA barcodes for 1/1000 of the animal kingdom. Biol. Lett., 6, 359-362 (2010).

Karthika, P., C. Vadivalagan, D. Thirumurugan and K. Murugan: Intraspecies variation and geographic differentiation among the populations of the quarantine agricultural pest Leucinodes orbonalis (Lepidoptera: Crambidae) in the global assemblage - a prospective of DNA barcoding. Mitochondrial DNA, 30, 682-693 (2019).

Kimura, M.: A simple method for estimating evolutionary rate of base substitutions through comparative studies of nucleotide sequences. J. Mol. Evol., 16, 111-120 (1980).

Leite, N.A., A. Alves-Periera, A.S. Corrêa, M.I. Zucchi and C. Omoto: Demographics and genetic variability of the New World Bollworm (Helicoverpa zea) and the Old World Bollworm (Helicoverpa armigera) in Brazil. PLOS ONE, 9, e113286 (2014).

Mitchell, A. and D. Gopurenko: DNA Barcoding the Heliothinae (Lepidoptera: Noctuidae) of Australia and utility of DNA Barcodes for pest identification in Helicoverpa and relatives. PLOS ONE, 11, e0160895 (2016).

Murray, M.G. and W.F. Thompson: Rapid isolation of high molecular weight plant DNA. Nucleic Acids Res., 8, 4312-4325 (1980).

Naik, V.C.B., P.P. Pusadkar, S.T. Waghmare, K.P. Raghvendra, S. Kranthi, S. Kumbhare, V.S. Nagrare, R. Kumar, T. Prabhulinga, N.G. Narkhedkar and V.N. Waghmare: Evidence of population expansion of Cotton pink bollworm Pectinophora gossypiella (Saunders) (Lepidoptera: Gelechiidae) in India. Sci. Rep., 10, e4740 (2020).

NCBI: National Center for Biotechnology Information. Available from: https://www.ncbi.nlm.nih.gov/ (Accessed on 18 June, 2018).

Nibouche, S., R. Bués, J.F. Toubon and S. Poitout: Allozyme polymorphism in the cotton bollworm Helicoverpa armigera (Lepidoptera: Noctuidae): Comparison of African and European populations. Heredity, 80, 438-445 (1998).

Passoa, S.C.: Identification guide to larval Heliothinae (Lepidoptera: Noctuidae) of quarantine significance. In: Leplntercept, An Identification Resource for Intercepted Lepidoptera Larvae (Eds.: T.M. Gilligan and S.C. Passoa). Identification Technology Program (ITP), USDA/APHIS/PPQ/S\&T, Fort Collins, CO, p. 19 (2014).

Ranjith, M.T. and M. Chellappan: DNA barcoding compliments morphological identification in tomato fruit borer, Helicoverpa armigera (Hübner) (Lepidoptera: Noctuidae). Entomon, 40, 125$138(2015)$.

Ranjith, M.T., A. Prabhuraj and Y.B. Srinivasa: Survival and reproduction of natural populations of Helicoverpa armigera on Bt-cotton hybrids in Raichur, India. Curr. Sci., 99, 1602-1606 (2010).

Rogers, A.R. and H. Harpending: Population growth makes waves in the distribution of pairwise differences. Mol. Biol. Evol., 9, 552-569 (1992).

Romeis, J. and T.G. Shanower: Arthropod natural enemies of Helicoverpa armigera (Hübner) (Lepidoptera: Noctuidae) in India. Biocontrol Sci. Technol., 6, 481-508 (1996).

Rozas, J., J.C. Sánchez-DelBarrio, X. Messeguer and R. Rozas: DnaSP, DNA polymorphism analyses by the coalescent and other methods. Bioinformatics, 19, 2496-2497 (2003).

Sambathkumar, S., C. Durairaj, S. Mohankumar, B. Preetha, R. Aravintharaj, N. Ganapathy and R. Surendran: Host induced 
genetic variation in legume pod borer, Maruca vitrata. J. Environ. Biol., 38, 1281-1291 (2017).

Sharma, H.C., C.P. Srivastava, C. Durairaj and C.L.L. Gowda: Pest management in grain legumes and climate change. In: Climate Change and Management of Cool Season Grain Legume Crops (Eds.: S.S. Yadav, D.L. McNeil, R. Redden and S.A. Patil). Springer Science, Dordrecht, Neatherlands, pp. 115-140 (2010).

Shashank, P.R., A.K. Chakravarthy, B.R. Raju and K.R.M. Bhanu: DNA barcoding reveals the occurrence of cryptic species in host associated population of Conogethes punctiferalis (Lepidoptera: Crambidae). Appl. Entomol. Zool., 49, 285-295 (2014).

Shashank, P.R., S. Twinkle, K. Chandrashekar, N.M. Meshram, S.S. Suroshe and A.S.R. Bajracharya: Genetic homogeneity in South American tomato pinworm, Tuta absoluta: A new invasive pest to oriental region. 3 Biotech, 8, 350 (2018).

Srivastava, C.P., N. Joshi and T.P. Trivedi: Forecasting of Helicoverpa armigera populations and impact of climate change. Indian J. Agric. Sci., 80, 3-10 (2010).

Subramanian, S. and S. Mohankumar: Genetic variability of the bollworm, Helicoverpa armigera, occurring on different host plants. J. Insect Sci., 6, 1-8 (2006).

Sun, Z.H., F.G. Luan, D.M. Zhang, M.J. Chen, B. Wang and Z.Z. Li: Genetic differentiation of Isaria farinosa populations in Anhui province of east China. Chinese J. Appl. Ecol., 22, 3039-3046 (2011).
Tajima, F.: Statistical method for testing the neutral mutation hypothesis by DNA polymorphism. Genetics, 123, 585-595 (1989).

Tamhankar, A.J, T.P. Rajendran, N.H.P. Rao, R.C. Lavekar, P. Jeyakumar, D. Monga and O.M. Bombawale: Variability in response to Helicoverpa armigera males from different locations in India to varying blends of female sex pheromones suggests male sex pheromones response polymorphism. Curr. Sci., 84, 448-450 (2003).

Tamura, K., G. Stecher, D. Petreson, A. Filipski and S. Kumar: MEGA6: Molecular Evolutionary Genetics Analysis Version 6.0. Mol. Biol. Evol., 30, 2725-2729 (2013).

Tay, W.T., M.F. Soria, T. Walsh, D. Thomazoni, P. Silvie, G.T. Behere, C. Anderson and S. Downes: A brave new world for an old world pest: Helicoverpa armigera (Lepidoptera: Noctuidae) in Brazil. PLoS ONE, 8, e80134 (2013).

Venkatesan, T., V. Sridhar, Y.R. Tomason, S.K. Jalali, G.T. Behere, R.M. Shanthi, R. Kumar, V.G. Vajja, P. Nimmakayala and U.K. Reddy: Use of expressed sequence tag microsatellite markers for population genetic research of Helicoverpa armigera (Lepidoptera: Noctuidae) from India. Can. Entomol., 148,187-199 (2016).

Xu, Y., J. Mai, B. Yu, H. Hu, L. Yuan, R. Jashenko and R. Ji: Study on the genetic differentiation of geographic populations of Calliptamus italicus (Orthoptera: Acrididae) in Sino-Kazakh border areas based on mitochondrial $\mathrm{COI}$ and COIl genes. J. Econ. Entomol., 112, 1912-1919 (2019). 